\title{
REMOVAL OF CHROMIUM HEXAVALENT IONS FROM AQUEOUS SOLUTION BY RETENTION ONTO IRON PHOSPHATE
}

\author{
F. GRANADOS-CORREA, ${ }^{*} J$. SERRANO-GÓMEZ
}

\author{
aInstituto Nacional de Investigaciones Nucleares. Departamento de Química, A. P. 18-1027. Col. Escandón, Delegación Miguel Hidalgo, \\ C. P. 11901, México, D. F., México.
}

(Received: June 9, 2009 - Accepted: May 13, 2010)

\begin{abstract}
Iron phosphate was synthesized and characterized for the removal of $\mathrm{Cr}(\mathrm{VI})$ ions from aqueous solution. Batch type experiments were conducted to study the effects of contact time, $\mathrm{pH}$ of the solution, chromium concentration and temperature. The experimental data were analyzed with the adsorption isotherms models of Freundlich, Langmuir and Dubinin Radushkevich (D-R). Results showed that $\mathrm{Cr}(\mathrm{VI})$ retention is dependent on $\mathrm{pH}$ and temperature. The thermodynamic parameters of the retention system were determined in a temperature interval from 293-323 K. The obtained values of thermodynamic parameters show that the $\mathrm{Cr}(\mathrm{VI})$ ions retention on iron phosphate is endothermic and spontaneous type. The results suggest that iron phosphate could be used as an effective adsorbent for the retention of $\mathrm{Cr}(\mathrm{VI})$ ions from aqueous solution.
\end{abstract}

Keywords: Iron phosphate; Chromium (VI) ion; Retention; Isotherms, Thermodynamic; XRD

\section{INTRODUCTION}

Water is an indispensable resource for all life form and is used in almost all human activities. Contamination of the water in rivers, lakes and seas alters the balance of the ecosystems, frequently causing irreversible phenomena that are reflected in life quality deterioration. This situation is in a large extent due to the technological development and the irrational management of the renewable resources. The presence of heavy metals in waste water originates from different industrial activities such as: minerals and metal industry, extractive metallurgy, tannery industry and fertilizer manufacture, among others; therefore, the industrial remainders constitute the main water contamination source. ${ }^{1-3}$

Different physical-chemical methods exist for treatment of liquid effluents that contain heavy metals, eg: precipitation, ion exchange and inverse osmosis; nevertheless, the majority of these processes are expensive to operate or maintain and their dependency with some factors does not allow removing metals in an efficient way. At the moment, the adsorption on inorganic solid has been the object of many investigations that allow diminishing contamination indices in effluents, because it is a precise and highly effective method for the metal removal in aqueous solution. The selection of an inorganic solid for removing polluting agents is based on its structural, superficial characteristics and selectivity, besides its stability to chemical processes, radiation and temperature. $^{4-6}$

Metal phosphates possessing remarkably large internal surface areas and narrow pore size distributions have attracted considerable attention for their great potential application as catalysts, adsorbents, and host materials. Recently, much work has been devoted to the metal phosphate materials synthesis, ${ }^{7-10}$ and iron phosphate with porous structure would be interesting in terms of structure and adsorbent performance. Thus, the study of $\mathrm{Cr}(\mathrm{VI})$ retention on iron phosphate materials is helpful and essential for the evaluation of heavy metal physic-chemical behavior in the aqueous pollutant retention field. Indeed, chromium retention is, now, well understood. ${ }^{11-21}$ However, the literature data indicate that the $\mathrm{Cr}(\mathrm{VI})$ retention on iron phosphate has not been studied.

On the other hand, chromium is considered as a highly dangerous polluting agent. Its concentrations in industrial effluents reach higher values than the allowed ones in many cases. Chromium toxicity depends strongly on its oxidation states, $\mathrm{Cr}(\mathrm{VI})$ being the most dangerous; besides, this polluting agent has been associated with the increase of cancer incidences. ${ }^{2}$

The objective of this investigation was to study the $\mathrm{Cr}(\mathrm{VI})$ ions retention behavior on iron phosphate, synthesized in our laboratories, as a function of chromium concentration, $\mathrm{pH}$ and temperature of the $\mathrm{Cr}(\mathrm{VI})$ aqueous solution, by means of batch experiments, to determine the optimal conditions of retention in the studied material and the thermodynamic parameters as well.

\section{EXPERIMENTAL}

Materials

All the reactives and chemical substances used in this investigation were analytical grade and deionized water was used in all the experiments to prepare working solutions.

Adsorbent preparation

In a typical sample preparation route, $8.08 \mathrm{~g} \mathrm{Fe}\left(\mathrm{NO}_{3}\right)_{3} .9 \mathrm{H}_{2} \mathrm{O}$ was dissolved in $80 \mathrm{~mL}$ of distilled water (solution A) and $7.16 \mathrm{~g} \mathrm{Na}_{2} \mathrm{HPO}_{4}$ dissolved in 80 $\mathrm{mL}$ of distilled water (solution $\mathrm{B}$ ). At once, solution $\mathrm{B}$ was added to solution A while stirring. The resulting $\mathrm{FePO}_{4}$ precipitate was recovered by centrifugation and washed with distilled water. The precipitate was suspended in $20 \mathrm{~mL}$ of distilled water, then a solution of $\mathrm{HF}(40 \mathrm{wt} \%)$ was dropped into the suspension under vigorous stirring. When a transparent solution was obtained, $2.88 \mathrm{~g}$ sodium dodecyl sulfate, dissolved in $10 \mathrm{~g}$ water, were added to the solution while stirring at room temperature for $30 \mathrm{~min}$. The resultant mixture was heated to $333 \mathrm{~K}$ and maintained for $2.5 \mathrm{~h}$. After cooling to room temperature, a light yellow precipitate was observed in solution and then recovered by centrifugation. The surfactant was removed from the solid by mixing it with $0.05 \mathrm{M}$ sodium acetate in ethanol and stirring at room temperature for 40 minutes. It was then separated by centrifugation, washed several times with ethanol and the resultant solid was dried at room temperature as described by Xuefeng et al. 2001.22

\section{Adsorbent characterization}

A Siemens D-5000 diffractometer coupled to a copper anode tube was used to obtain the X-ray diffraction pattern and identify the crystalline compound. The $\mathrm{K}_{\mathrm{a}}$ wavelength was selected with a diffracted beam monochromator. The compound was identified comparing it with JCPDS cards in the conventional way. Morphology was studied using a scanning electron microscope (SEM) Philips XL-30 and specific surface areas were obtained by nitrogen adsorption through the BET method with a surface area analyzer Micromeritics Gemini. Stock and subsequent solutions of $\mathrm{Cr}(\mathrm{VI})$ were prepared by dissolving $\mathrm{K}_{2} \mathrm{Cr}_{2} \mathrm{O}_{7}$ (analytic reactive grade) in deionized water. The solutions with the desired $\mathrm{Cr}(\mathrm{VI})$ concentrations were prepared by successive dilutions of a stock solution. The $\mathrm{pH}$ of the chromium solutions was adjusted adding $\mathrm{NH}_{4} \mathrm{OH}$ or $\mathrm{HNO}_{3}$. The present chromium concentrations in each aliquot were determined by reaction with 1.5 diphenylcarbazide ${ }^{23}$ followed by absorbance measurement at $540 \mathrm{~nm}$ using a UV-visible spectrophotometer Shimadzu model 265.

\section{Batch experiments}

Batch type experiments were carried out at $293 \mathrm{~K}$ to determine the retention kinetic of $\mathrm{Cr}(\mathrm{VI})$ ions onto iron phosphate. $100 \mathrm{mg}$ of iron phosphate 
and $10 \mathrm{~mL}$ of $1.0 \times 10^{-4} \mathrm{~mol} / \mathrm{L} \mathrm{Cr}(\mathrm{VI})$ ions solution (pH 5) were shaken in closed vials for different time intervals ( $5 \mathrm{~min}$ to $24 \mathrm{~h}$ ) to attain equilibrium distribution. ${ }^{24}$ Later, the samples were centrifuged to recover the liquid phase. All of the experiments were performed in duplicate, by running two parallel independent closed vials, simultaneously. The retention capacity of $\mathrm{Cr}(\mathrm{VI})$ ions by iron phosphate was determined from the difference between the initial and final concentrations of $\mathrm{Cr}(\mathrm{VI})$ ions in the aqueous solutions before and after retention. The amount of $\mathrm{Cr}(\mathrm{VI})$ ions retained per unit mass of the adsorbent and the percent retention of $\mathrm{Cr}(\mathrm{VI})$ ions were calculated by:

$$
\begin{gathered}
q=\frac{\left(C_{o}-C_{e}\right) V}{m} \\
\text { \%Retention }=\frac{\left(C_{i}-C_{f}\right)}{C_{i}} \times 100
\end{gathered}
$$

were, $q$ is the amount of $\mathrm{Cr}(\mathrm{VI})$ ions retained on iron phosphate $(\mathrm{mmol} / \mathrm{g})$, $C_{o}$ and $C_{e}$ are the initial and equilibrium concentration of solution $(\mathrm{mol} / \mathrm{L}), C_{i}$ and $C_{f}$ are the initial and final solution phases concentration (mol/L), $V$ is the volume of solution (L) and $m$ is amount of adsorbent (g). For the chromium concentration studies, solutions with the desired concentrations $\left(10^{-4}-10^{-5}\right.$ $\mathrm{mol} / \mathrm{L})$ of $\mathrm{Cr}(\mathrm{VI})$ ions were prepared by successive dilutions of a $1.0 \times 10^{-4}$ $\mathrm{mol} / \mathrm{L} \mathrm{K}_{2} \mathrm{Cr}_{2} \mathrm{O}_{7}$ stock solution.

\section{RESULTS}

\section{Adsorbent characterization}

The obtained iron phosphate X-ray diffraction pattern of synthesized material sample shows that iron phosphate was identified as amorphous structure (Fig. 1). The presence of unclear and asymmetric lines indicates a low crystalinity. On the other hand, the XRD pattern of iron phosphate obtained after of the $\mathrm{Cr}(\mathrm{VI})$ retention shows no important change, therefore the amorphous structure of the compound was confirmed. The particles of the iron phosphate observed by SEM were porous. The Specific surface area of iron phosphate was $269.5 \mathrm{~m}^{2} / \mathrm{g}$, the total pore volume was $0.3150 \mathrm{~cm}^{3} / \mathrm{g}$ and the average pore diameter was $2.33 \mathrm{~nm}$. In general, those results are within the range reported in literature for this compound, ${ }^{25}$ besides those textural characterizations shows that the iron phosphate can provide the active sites for their $\mathrm{Cr}(\mathrm{VI})$ retention from aqueous solution.

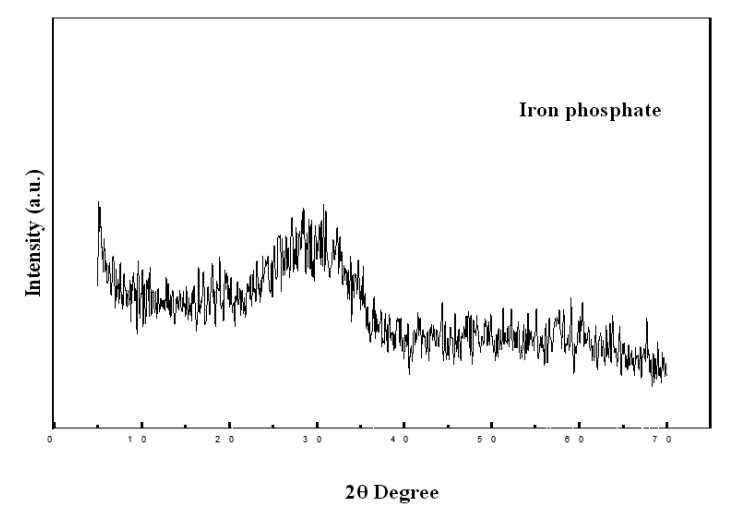

Fig. 1: Iron phosphate X-ray diffraction pattern.

\section{Effect of contact time}

The $\mathrm{Cr}(\mathrm{VI})$ retention on iron phosphate was carried out by means of static experiments at an initial $\mathrm{pH}$ of 5.0, using a $1 \times 10^{-4} \mathrm{~mol} / \mathrm{L} \mathrm{K}_{2} \mathrm{Cr}_{2} \mathrm{O}_{7}$ solution at room temperature. The results shown in Fig. 2 indicate that the $\mathrm{Cr}(\mathrm{VI})$ retention on iron phosphate was fast and reached complete equilibrium within 5 hours of shaking time. A maximum retention capacity of $\mathrm{Cr}(\mathrm{VI})$ was found to be $9.47 \mathrm{x}$ $10^{-4} \mathrm{meq} / \mathrm{g}$ which indicates a good retention of $\mathrm{Cr}(\mathrm{VI})$ ions.

In order to justify the validity of iron phosphate as an adsorbent for $\mathrm{Cr}(\mathrm{VI})$ ions retention, its retention capacity at equilibrium was compared with those capacities of other adsorbents such as boehmite: $8.44 \times 10^{-5} \mathrm{meq} / \mathrm{g}{ }^{21}$ and calcium phosphate: $2.41 \times 10^{-4} \mathrm{meq} / \mathrm{g}$ used to remove $\mathrm{Cr}(\mathrm{VI})$ from aqueous solutions. ${ }^{26}$ As can be observed, iron phosphate has the best performance to retain $\mathrm{Cr}(\mathrm{VI})$ ions.

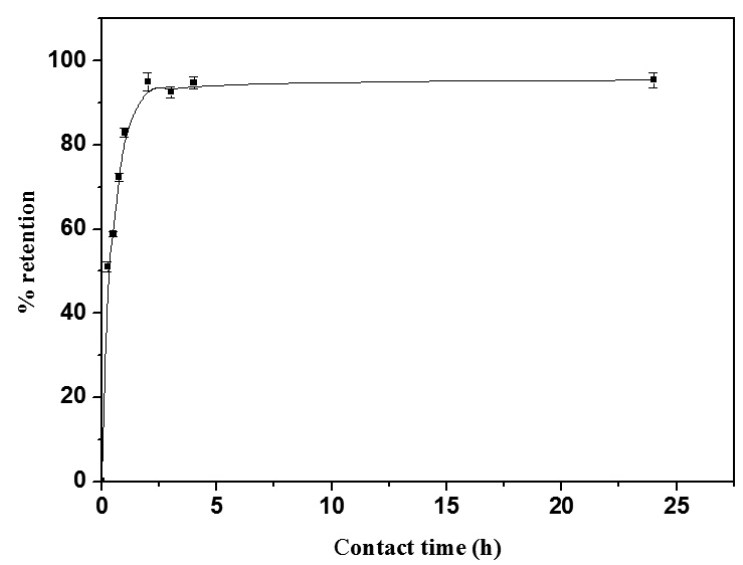

Fig. 2: $\mathrm{Cr}(\mathrm{VI})$ retention on iron phosphate as a function of contact time.

\section{Effect of $\mathrm{pH}$}

The influence of initial $\mathrm{pH}$ on the chromium ion retention was studied using a $1 \times 10^{-4} \mathrm{~mol} / \mathrm{L}$ chromium ion solution. The initial $\mathrm{pH}$ of the chromium solutions was adjusted ranging from 3 to 11 using $\mathrm{HNO}_{3}$ and $\mathrm{NaOH}$ solutions and the obtained results are shown in Fig. 3. The chemical species of metal studied are anions and thus the retention decreased when alkaline $\mathrm{pH}$ was increased, while the maximum chromium retention occurs at $\mathrm{pH}$ acid values. This maximum retention occurs in acid media due to the fact that in this media the chromium ions exist as the anions $\mathrm{HCrO}_{4}^{-}$or $\mathrm{Cr}_{2} \mathrm{O}_{7}^{2-, 21,27}$ which are adsorbed on the charged positively surface of iron phosphate, leading to a high retention percentage. In alkaline media, the competence between $\mathrm{Cr}_{2} \mathrm{O}_{7}{ }^{2-}$ and $\mathrm{OH}^{-}$ions to displace the $\mathrm{OH}$ groups attached to the $\mathrm{Fe}$ atoms of the adsorbent can explain the observed low $\mathrm{Cr}(\mathrm{VI})$ ion retention. On the other hand, inorganic materials surfaces acquire electrical charge when interacting with solutions. The type of charge is variable and depends on solution $\mathrm{pH}$ and zpc (zero point charge) of the material. The reported zpc value for iron phosphate is 5.3. ${ }^{28}$ Only cationic species should be retained on the inorganic material above its zpc value. Under our experimental conditions, the hexavalent chromium anions species $\left(\mathrm{HCrO}_{4}^{-}\right.$or $\left.\mathrm{Cr}_{2} \mathrm{O}_{7}^{2-}\right)$ are the only one that appears in the original solution of $\mathrm{pH} 5.0$, acording at the relative distribution of $\mathrm{Cr}(\mathrm{VI})$ species in the aqueous solution at the chromium concentration studied ${ }^{29}$ as shown in Fig. 4. Therefore, anionic $\mathrm{Cr}(\mathrm{VI})$ species should be retained on the positively charged surface of iron phosphate. In all experiments, $\mathrm{pH} 5.0$ was used except in the $\mathrm{pH}$ effect study, thus guaranteeing that the iron phosphate surface was positively charged during the retention experiments. The results demonstrate that the electrical properties of this material surface, i. e. the charge of the surface groups, are in part responsible for ion exchange with a specific group on a retention surface, in accordance with the concept of zpc. ${ }^{30}$

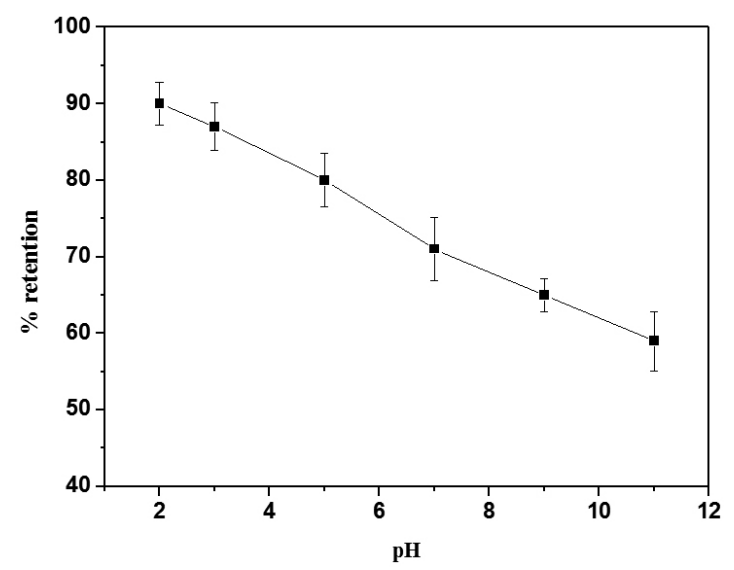

Fig. 3: $\mathrm{pH}$ influence on $\mathrm{Cr}(\mathrm{VI})$ retention on iron phosphate. 


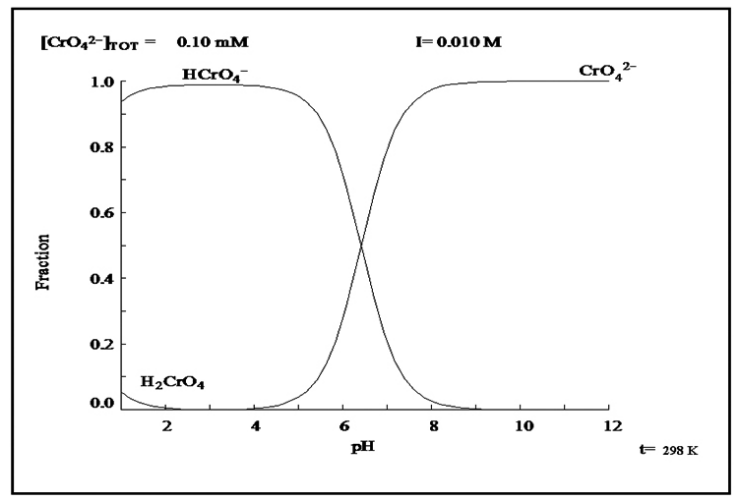

Fig. 4: Relative distribution diagram of $\mathrm{Cr}(\mathrm{VI})$ species in the aqueous solution

Effect of initial concentration

The chromium retention on the synthesized iron phosphate was studied using several concentrations ( $1 \times 10^{-4}$ to $\left.1 \times 10^{-5} \mathrm{~mol} / \mathrm{L}\right)$ at room temperature and a shaking time of $5 \mathrm{~h}$ as shown in Fig. 5. It was found that $\mathrm{Cr}(\mathrm{VI})$ adsorption is increased when the chromium concentration decreases; this behavior is attributed to the fact that there are more active sites in the adsorbent material surface per adsorbent gram available for the chromium retention at a high dilution.

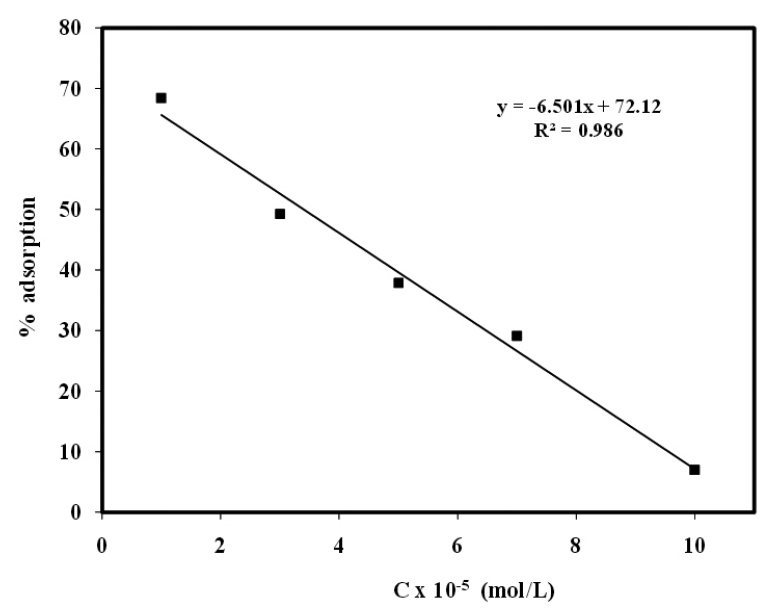

Fig. 5: Concentration effect of $\mathrm{Cr}(\mathrm{VI})$ retention on iron phosphate

Adsorption isotherms

The distribution of $\mathrm{Cr}(\mathrm{VI})$ between the liquid phase and the solid adsorbent phase (iron phosphate) as a function of initial concentration, was surveyed using isotherms models of Freundlich, Langmuir and Dubinin-Radushkevich (D-R). The Freundlich model was evaluated by means of the following equation ${ }^{31}$ :

$$
\log a_{e}=1 / n \log C_{e}+\log K
$$

where $\log a_{e}$ is the amount of solute retained per unit weight of the adsorbent at equilibrium ( $\mathrm{mol} / \mathrm{g}), C$ is the solute concentration in solution at equilibrium (mol/L), $K$ and $1 / n$ are the Freundlich constants that correspond to retention intensity and retention capacity respectively. The values of $1 / n$ and $K$ numerically represent an affinity of adsorbent with adsorbate and a relationship of adsorbate-adsorbent affinity to which the volume of adsorbate is added, respectively. When constant $1 / n$ is in the range $0.1-0.5$, it is considered that adsorbate is easily adsorbed, on the other hand, if $1 / n>2$, it is considered that adsorption is difficult. The values of $K$ and $1 / n$ were obtained from the slope and intercept of a plot of $\log a_{e}$ vs $\log C_{e}$ as shown in Fig. 6 and they were found to be $0.24 \pm 0.002 \times 10^{-2} \mathrm{~mol} / \mathrm{g}$ and $0.68 \pm 0.02 \mathrm{~mol} / \mathrm{g}$, respectively, with a correlation coefficient $\mathrm{R}^{2}=0.9860$. This empirical model can be applied for an ideal retention on heterogeneous surfaces and for an adsorption in multilayers as well. Relatively high fractional values of $1 / n(0-1)$ demonstrate a validity of the classic Freundlich isotherm on the interval of studied chromium concentration. The value obtained for $1 / n$ was attributed to the heterogeneous nature of the adsorbent surface with an exponential distribution of the retention sites..$^{32}$ As can be observed in Fig. 6, a straight line was obtained with a high correlation factor $(0.9860)$, indicating that the retention data fit well to the Freundlich isotherm model.

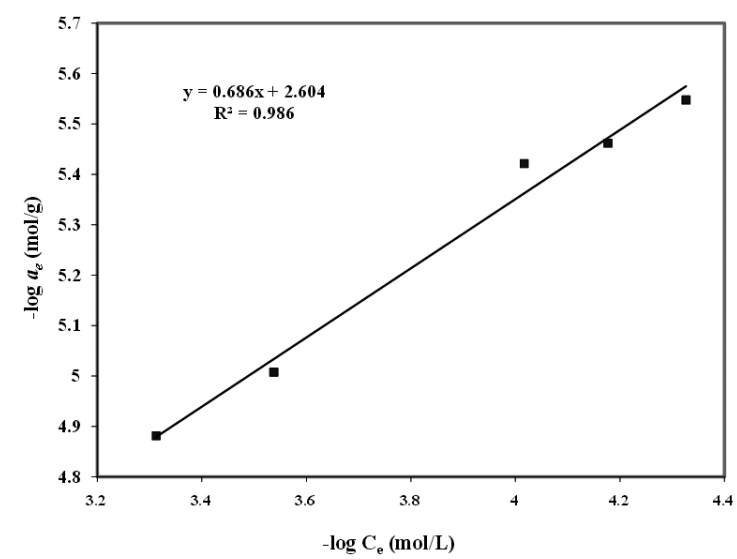

Fig. 6: Freundlich adsorption isotherm for $\mathrm{Cr}(\mathrm{VI})$ retention on iron phosphate.

The retention data also were evaluated using the Langmuir adsorption isotherm in their linearized form:

$$
\frac{C_{e}}{a_{e}}=\frac{1}{K a_{\max }}+\frac{C_{e}}{a_{\text {máx }}}
$$

where $C$ is the metallic ion concentration in solution at equilibrium $(\mathrm{mol} / \mathrm{L}), a_{e}$ is the amount of chromium retained at equilibrium $(\mathrm{mol} / \mathrm{g}) ; K$ and $a$ are the Langmuir constants and the retention maximum capacity respectively. The Langmuir model is extensively applied for an adsorption isotherm; this model considers that the adsorption energy of each molecule is independent of the surface material, retention only takes place on some sites and there is no interaction between molecules. A straight line was obtained when $C / a$ was plotted vs $C$ on the investigated interval of concentration (Fig. 7 ), and indicates that the $\mathrm{Cr}(\mathrm{VI})$ ion retention also obeys the Langmuir model. The slope of the straight line was $a_{\text {mix }}=(2.4 \pm 0.01) \times 10^{-5} \mathrm{~mol} / \mathrm{g}$ and the intercept was $K=(23.69 \pm 0.1) \times 10^{2} \mathrm{~L} / \mathrm{mol}$, with a correlation coefficient of $\mathrm{R}^{2}=0.9089$.

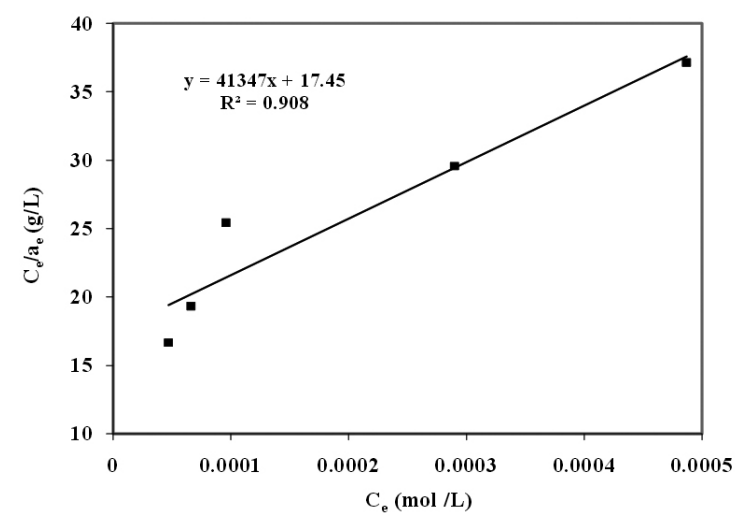

Fig. 7: Langmuir adsorption isotherm for $\mathrm{Cr}(\mathrm{VI})$ retention on iron phosphate.

On the other hand, data were also evaluated with the Dubinin-Radushkevich (D-R) adsorption isotherm in their linearized form ${ }^{32}$ : 


$$
\ln C_{e}=\ln a_{\max }-\beta \varepsilon^{2}
$$

where $\beta$ is a constant and $\varepsilon$ is the Polanyi retention potential that can be calculated with the following equation:

$$
\varepsilon=R T \ln \left(1+1 / C_{e}\right)
$$

where $R$ is the gases constant $\left(8.314 \times 10^{-3} \mathrm{~kJ} / \mathrm{mol} \mathrm{K}\right)$ and $T$ is the absolute temperature in Kelvin. This isotherm postulates a fixed volume or "adsorption space" close to the adsorbent surface where adsorption takes place. Polanyi adsorption potential, $e$, is the work required to remove a molecule or ion to infinity from its location in adsorption space independent of temperature. This model assumes the heterogeneity of adsorption energies within this space. The Dubinin-Radushkevich equation was formulated from Polanyi theory especially for applications in microporous materials, however it can be applied to experimental data for low concentrations of adsorbates and very good correlations can be obtained. A graph of $\ln a$ vs. $\varepsilon^{2}$ is shown in Fig. 8. A straight line was obtained and this indicates that the adsorption data also fit the D-R adsorption model in the studied $\mathrm{Cr}(\mathrm{VI})$ concentration range. The obtained values of maximum amount of chromium that can be adsorbed on iron phosphate and the average adsorption energy, obtained from the slope and interception of this straight line, were $a_{\text {sic }}=(1.2 \pm 0.04) \times 10^{-4} \mathrm{~mol} / \mathrm{g}$ y $E=$ $0.0236 \pm 0.10 \mathrm{~kJ} / \mathrm{mol}$ respectively. The average adsorption energy $(E)$, which is the averaged free energy for transference of one mol of solute from the infinite (present in solution) to the iron phosphate surface, was evaluated using the relation $E=1 / \sqrt{ }-2 \beta$ with $\beta=-890.2 \mathrm{~mol}^{2} / \mathrm{K} \mathrm{J}$. The value obtained from $E$ can be in the interval $8-16 \mathrm{~kJ} / \mathrm{mol}$ for a process of ion exchange. ${ }^{33} \mathrm{As} E=0.0236 \pm 0.10$ $\mathrm{kJ} / \mathrm{mol}$ is lower than the interval $8-16 \mathrm{~kJ} / \mathrm{mol}$, the retention process is not controlled by an ion exchange process. The low value of adsorption energy found for the present system, indicates that the forces of attraction that work during the $\mathrm{Cr}(\mathrm{VI})$ adsorption on iron phosphate are relatively no stronger and the adsorption process can occur even under ordinary condition.

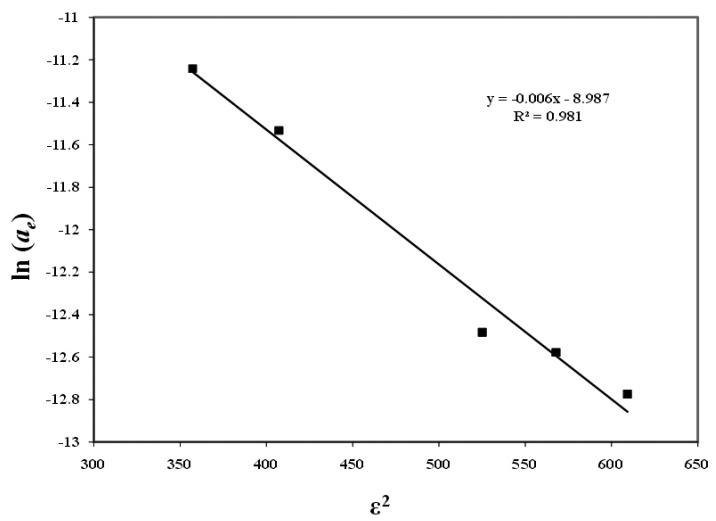

Fig. 8: Dubinin-Radushkevich (D-R) adsorption isotherm for $\mathrm{Cr}(\mathrm{VI})$ retention on iron phosphate

\section{Temperature effect}

Batch experiments were carried out at 293, 303, 313 and $323 \mathrm{~K}$ to investigate the temperature effect with an initial $\mathrm{Cr}(\mathrm{VI})$ ion concentration of $1 \times 10^{-4} \mathrm{~mol} / \mathrm{L}$ at pH 5 , a contact time of $5 \mathrm{~h}$ and an adsorbent amount of $0.1 \mathrm{~g}$. It was observed that the $\mathrm{Cr}(\mathrm{VI})$ retention is increased with the increase in temperature as shown in Table 1. This behavior is provoked by the great mobility of $\mathrm{Cr}(\mathrm{VI})$ ionic species present in aqueous solution and the possible acceleration of some adsorption passages which are originally slow or by the creation of some new active sites on the iron phosphate surface with increase in temperature. On the other hand, this can also be explained by the fact that at high temperature the kinetic energy of $\mathrm{Cr}_{2} \mathrm{O}_{7}{ }^{2-}$ anions is high, therefore contact between anionic chemical species and the active sites of iron phosphate is sufficient, leading to an increase in retention efficiency.
Table 1. Temperature effect on the percentage of $\mathrm{Cr}(\mathrm{VI})$ retained at equilibrium on the synthesized iron phosphate.

\begin{tabular}{lcccc}
\hline Temperature $\quad(\mathrm{K})$ & 293 & 303 & 313 & 323 \\
& & & & \\
Retention percentage & $47.5 \pm 0.1$ & $62.0 \pm 0.2$ & $72.8 \pm 0.6$ & $90.0 \pm 0.9$
\end{tabular}

Data of chromium retained at equilibrium and at different temperatures have been used to evaluate the thermodynamic parameters $\Delta H^{0}, \Delta S^{0}$ and $\Delta G^{0}$ for the retention system by using the following equations:

$$
\begin{aligned}
& \log K_{d}=-\frac{\Delta H^{0}}{2.303 R}\left(\frac{1}{T}\right)+\frac{\Delta S^{0}}{2.303 R} \\
& \Delta G^{0}=-R T \ln K_{d} \\
& \Delta G^{0}=\Delta H^{0}-T \Delta S^{0} \\
& K_{d}=\frac{\left(C_{i}-C_{f}\right)}{C_{i}} \frac{V}{m}
\end{aligned}
$$

where $\Delta H^{0}, \Delta S^{0}, \Delta G^{0}, T, K_{d}$ and $R$ are, respectively, enthalpy change, entropy change, Gibbs energy of retention, absolute temperature in Kelvin, the universal gases constant and distribution coefficient, respectively. For $K_{d}$ formula, $m$ is the mass of the adsorbent in grams, $V$ is the volume of the chromate solution contacted with the solid, and $C_{i}$ and $C_{f}$ were defined in the experimental section. The enthalpy change was calculated from the obtained straight line slope in the plot $K_{d} v s 1 / T$ (Fig. 9), derived from application of the van't Hoff equation in its linearized form ${ }^{33,34}$ :

The obtained enthalpy change $\left(\Delta H^{0}\right)$ was found to be $45.9 \pm 0.3 \mathrm{~kJ} / \mathrm{mol}$, where the positive value indicates an endothermic nature of the retention process. The magnitude of $\Delta H^{0}$ is related to the reaction mechanism. If $\Delta H^{0}$ is in the range of $8-16 \mathrm{~kJ} / \mathrm{mol}$, retention is controlled by ion exchange ${ }^{33}$ and thus, for the $\mathrm{Cr}_{2} \mathrm{O}_{7}^{2-}$ ion retention process on $\mathrm{FePO}_{4}$, ion exchange is not dominant according to the value of $\Delta H^{0}$ found in this work.

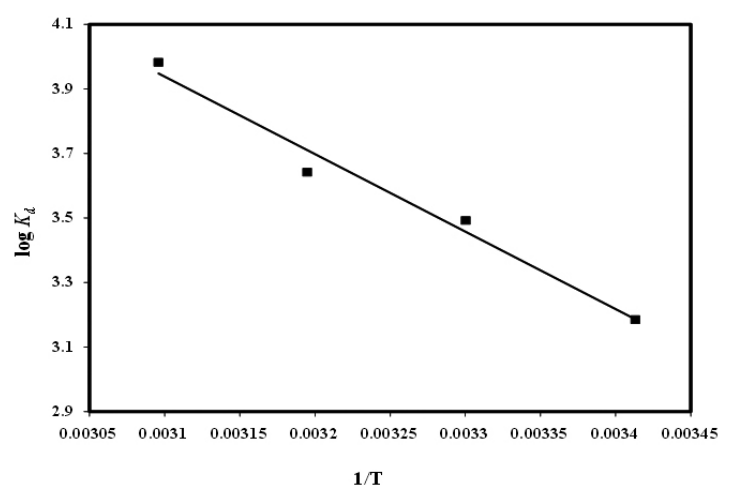

Fig. 9: Plot of $\log K_{d}$ vs.1/T for the $\mathrm{Cr}(\mathrm{VI})$ retention on iron phosphate.

The $\Delta S^{0}$ value also was calculated from line intercept with the $y$ axis in Fig. 9, whereas $\Delta G^{0}$ was obtained using the equation (9). $\Delta G^{0}$ was calculated as $-17.8 \pm 2.0 \mathrm{~kJ} / \mathrm{mol}$; their negative sign and value show the spontaneity of retention process. Meanwhile $\Delta S^{0}$ was obtained as $(21.7 \pm 0.2) \times 10^{-2} \mathrm{~kJ} / \mathrm{K} \mathrm{mol}$ and their positive value indicates an increase in the randomness in solution interphase with solid by the ions chromium fixation on iron phosphate. When ions are retained at the iron phosphate surface, water molecules that were previously bounded to $\mathrm{Cr}(\mathrm{VI})$ ions are released and dispersed in the solution, resulting in an increase in entropy change.

The described results indicate that iron phosphate is an adequate adsorbent for removal of $\mathrm{Cr}(\mathrm{VI})$ ions from aqueous solutions under the test experimental 
conditions. The benefits and novelty of using iron phosphate instead of other solid studied and reported in the literature, ${ }^{35-36}$ include low cost and its thermal stability, chemical resistance and low solubility in a wide $\mathrm{pH}$ interval.

\section{CONCLUSIONS}

The iron phosphate was synthesized and characterized in this investigation and an amorphous material was obtained. The equilibrium system was obtained at short time of $5 \mathrm{~h}$ by placing solid and aqueous phases in contact. $\mathrm{Cr}(\mathrm{VI})$ retention on synthesized material was dependent on adsorbate concentration, temperature and $\mathrm{pH}$. The $\mathrm{Cr}(\mathrm{VI})$ retention data fitted best to the isotherm model of Freundlich, indicating that the chromium retention on iron phosphate surface occurs through the formation of multilayers. The $\Delta H^{0}, \Delta S^{0}$ and $\Delta G^{0}$ values indicate that the chromium ion retention on iron phosphate was carried out by means of an endothermic and spontaneous retention process and by means of a physical retention that is determined by its activation energy.

\section{ACKNOWLEDGEMENTS}

The financial support of CONACYT with the project 52658-II and project ININ CB-718 is gratefully acknowledged.

\section{REFERENCES}

1. G. Fellenberg, The chemistry of pollution, J. Willey, Chinchester, England, 2000.

2. Toxicological Review of hexavalent chromium, U.S. Environmental Protection Agency, National Center for Environmental Assessment, Office of Research and Development, Washington, DC, 1998.

3. B.J. Alloway, A.K. Ayres, Chemical principles of environmental pollution, second ed., Blakie A\&P, London, 1997.

4. S. Mor, K. Ravindra, N.R. Bishnoi, Chem. Rev. 96, 3327, (1996).

5. S. Debnath, U. C. Ghosh, J. Chem. Thermod. 40, 67, (2008).

6. N. Spanos, S. Slavov, Ch. Kordulis, A. Lycourghiotis, Langmuir. 10, 3134, (1994).

7. F. Schuth, Chem. Mater, 13, 2885, (2001).

8. C. Pan, W. Zhang, Y. Wang, Z. Zhou, D. Jiang, S. Wu, T. Wu, Mater, Lett. 57, 3815, (2003).

9. L. Gang, J. Mingjun, Z. Zhou, Z. Wenxiang, W. Tonghao, J. Dazhen, Chem. Commun. 1660, 1660, (2004)

10. F. Granados-Correa, J. Bonifacio-Martínez, J. Serrano-Gómez, J. Chil. Chem. Soc. 53, 252, (2009).

11. F. Shafqat, Q.N. Bhatt, M.A. Hanif, A. Zubair, J. Chil. Chem. Soc. 53, $1667,(2008)$.
12. P.A. Kumar, M. Ray, S. Chakraborty, J. Hazard. Mater. 143, 24, (2007).

13. F. Gode, E. Moral, Bioresource Technol. 99, 1981, (2008).

14. A. M. F. Orozco, E. M. Contreras, N.E. Zaritzky, J. Hazard. Mater. 150, 46, (2008).

15. D. Tiwari, S.P. Mishra, M. Mishra, R.S. Dubey, Appl. Radiat. Isotopes. 50, 631, (1999).

16. S.P. Mishra, V.K. Singh, D. Tiwari, Radiochim. Acta. 81, 227, (1998).

17. S. Bendezú, J. Oyague, A. Romero, R. García, Y. Muñoz, N. Escalona, $J$. Chil. Chem. Soc. 50, 677, (2005).

18. H. Parab, S. Joshi, N. Shenoy, A. Lali, U.S. Sarma, M. Sudersanan, Process Biochem. 41, 609, (2006).

19. F. Venditti, A. Ceglie, G. Palazzo, G. Colafemmina, F. Lopez, J. Colloid. Interf. Sci. 310, 353, (2007).

20. G. Arthanareeswaran, P. Thanikaivelan, N. Jaya, D. Mohan, M. Raajenthiren, J. Hazard. Mater. 139, 44, (2007).

21. F. Granados-Correa, J. Jiménez-Becerril, J. Hazard. Mater. 162, 1178, (2009).

22. G. Xuefeng, D. Weiping, W. Xueguang, Y. Quijie, Chem. Comm. 8, 709, (2001).

23. ASTM D 1687-92, Chromium in water, test method A, (1996).

24. F. Granados-Correa, J. Serrano-Gómez, Sep. Sci. Technol. 44, 924, (2009).

25. R. P. Unnikrishnan, E. Sahle-Demessie, Chem. Comm. 9, 826, (2004).

26. F. Granados-Correa, J. Bonifacio-Martínez, J. Serrano-Gómez, Rev. Int. Contam. Ambient. 26, 129, (2010).

27. F.C. Baes, R.E. Mesmer, The hydrolysis of cations, John Wiley and Sons Inc., New York, 1976.

28. V. Thinnappan, C.M. Merifield, F.S. Islam, D.A. Polya, P. Wincott, R.A. Wogelius, Appl. Geochem. 23, 3187 (2008).

29. I. Puigdomenech, Program MEDUSA: Make Equilibrium Diagrams Using Sophisticated Algorithms). http:/www.inorg.Kth.se/Research/Ignasi;/ Oindex.html (1999).

30. N. Rosas-Gutiérrez, F. Granados-Correa, S. Bulbulian, Int. Nucl. Chem. Soc. News. 6, 34, (2009).

31. Bitton, G., Formula Handbook for Environmental Engineers and Scientist, John Wiley and Sons Inc., New York, 1998.

32. F. Granados-Correa, J. Jiménez-Becerril, Radiochim. Acta. 92, 105, (2004).

33. F. Helfferich, Ion exchange, Mc Graw Hill, New York, 1962.

34. F. Granados-Correa, J. Serrano-Gómez, J. Radioanal. Nucl. Chem. 268, 95, (2006)

35. D. Aggarwal, M. Goyal, R. C. Bansai, Carbon 37, 1989, (1999).

36. K. Kelvi, S. Pattabhi, K. Kadirvelu, Bioresource Technol. 80, 87, (2001). 